\title{
Brucellosis in Nepal : A Potential Threat To Public Health Professionals
}

\author{
Acharya Krishna Prasad, Ph.D ${ }^{1,2}$
}

'Animal Science Instructor, Shree Himganga Higher Secondary School, Ramechhap, Nepal

${ }^{2}$ Institute of Agriculture and Animal Science, Tribhuwan University, Rampur, Chitwan, Nepal

\section{A B S T R A C T}

Brucellosis is a prominent zoonotic disease affecting humans and animals which with the lack of proper diagnosis and treatment remains dangerous in third world countries like Nepal. Currently, Brucellosis poses a public health concern, whose incidences among entire herds of animals can present substantial economic and health burdens for herders and health professionals. Additionally, factors such as close contact with animals, poor animal husbandry, unhygienic feeding habits, and pre-existing health problems (e.g. diabetes, sickle-cell anemia) can exacerbate the spread of Brucella and related zoonotic agents. In Nepal, serious cases of bovine and even human brucellosis have been reported, although the topic is yet to be extensively reviewed. This paper evaluates the literatures on human and animal brucellosis in Nepal and other countries, with an emphasis on the impact of Brucella outbreaks on public health professionals. Herein, we summarize the current status of the disease, the mechanism of infection, pathogenesis, zoonotic potential, diagnostic advances, treatment regimens, and the preventive measures that can be adopted in managing human brucellosis in under-developed countries such as Nepal. JMS 2015; 18(2):138-149.

Keywords: Brucellosis; zoonotic status; Public health professionals, Nepal.

\section{INTRODUCTION}

Brucellosis is a major abortifacient zoonotic disease of livestock with worldwide distribution ${ }^{[1,2]}$. Brucella abortus that cause bovine brucellosis along two other Brucella species namely B. melitensis and B.suis, is of veterinarian importance and human brucellosis inveterinary and are highly pathogenic that cause miscarriage in second half of pregnancy, infertility in females and sterility in males their natural hosts ${ }^{[2-4]}$. Establishment of the carrier state in a large proportion of animals can lead to a significant reduction in milk yield which together with losses through abortion or early calf death due to $B$. abortus infection is a huge economic constraint for farmers ${ }^{[5,6]}$. In regions where disease surveillance and control measures are not instigated, long-term chronic infections are often associated

\footnotetext{
Correspondence

Dr. Acharya Krishna Prasad, Ph.D ${ }^{1,2}$

1. Animal Science Instructor, Shree Himganga Higher Secondary School, Ramechhap, Nepal;

2. Institute of Agriculture and Animal

Science, Tribhuwan University, Rampur, Chitwan, Nepal

E-Mail : kriaasedu@gmail.com
}

with carpal hygromas and infertility ${ }^{[1,7]}$. Disease presentations in bulls include orchitis, epididymitis and seminal vesiculitis ${ }^{[4,6,8]}$. Brucellosis is a major public and animal health problem in areas with intensive mixed types of farming and where owners cohabit with their animals during night ${ }^{[2,9,10]}$. The mixed, migratory and free roaming nature of the livestock herding makes it unpractical to separate the suspected and healthy animals thus ensuring a favorable environment for Brucella transmission. In Nepal, brucellosis is a serious public health threat posed by endemic bovine and caprine brucellosis. Recent cases of and is easily spread by licking of para-veterinary students have been alarmingly serious. A systematic and large scale brucellosis control program targeting the eradication of the disease has not been adopted in Nepal. Financial constraints, inadequate laboratory facilities, lack of compliance by the farmers and religious taboo have been major hurdles that impede the success of Brucella eradication in Nepal. Presently, control measures have been implemented in only few commercial farms. However, lack 
of precise information on the distribution, public health and economic impact of brucellosis is attributed to disease of low priority by policy makers and limited resources allocated for the control of this disease.

Though it has been widely reported in various species of animals and humans, there is a dearth of literature addressing this disease in the very context of Nepal. Thus, the main purpose of this article is to review the extensive literatures available so far and suggests some guidelines that fit the context of Nepal.

\section{Transmission}

Chronically infected cattle may shed the organism via milk and reproductive tract discharges ${ }^{[11-13]}$, and can also vertically transmit infection to subsequently born calves, thereby maintaining disease transmission ${ }^{[1,14]}$. Aborted fetuses from infected animals contain huge numbers of infectious organisms and if not properly disposed form a major source of contamination ${ }^{[15]}$. The pathogen is highly contagious macrophages and other cell types leads infected animals and abortion materials ${ }^{[16,17]}$, and abortion materials, discharges and waste of infected animals may contaminate stables, meadows, food supplies and water sources ${ }^{[18,19]}$. Direct contact with infected animals and consumption of contaminated dairy products may cause infection in human beings ${ }^{[20,21]}$. Human to human transmission is relatively uncommon ${ }^{[22]}$; however, it had been reported to develop after blood marrow transplantation ${ }^{[23]}$, sexual intercourse ${ }^{[24]}$, and also following blood transfusions ${ }^{[25]}$. Animals in Nepal are often housed in unhygienic sheds with poor management systems and also in close association (some sharing the same roof) with eachother. This presents significant risk factors for the contraction of brucellosis in humans. Similarly the consumption of raw milk, liver, spleen, udder, kidney and testis and handling of dung, which is widely prevalent in Nepal, may also serve as source of hazard. Practices like Yak's raw blood consumption on fastive scale also pose a threat yet to be studied.

\section{Pathogenesis And Immune Response}

The ability of the pathogen to survive and replicate within different host cells explains its pathogenicity ${ }^{26,27}$. The pathogenesis depends upon various factors such as the species, size of innoculum, modes of transmission and immune status of host ${ }^{28}$. Extensive replication in placental trophoblasts is associated with abortion ${ }^{[1,28,29]}$, and persistence in increasing in Eastern Mediterranean to chronic infections ${ }^{[30-32]}$. Protective immunity to the host is conferred by $\mathrm{T}$ - cell mediated macrophage activation by antigenic protein of Brucella and production of corresponding antibody along with involvement of various players such as Tumor Necrosis factor (TNF), interferons and complements. Following infection, Ig $\mathrm{M}$ titer increases initially followed by $\operatorname{Ig} \mathrm{G}$ titer. Thus, the apperance of $\operatorname{IgM}$ indicates immune response against brucellosis and $\mathrm{IgG}$ correspondingly indicates chronic infection or relapsed form $^{[33]}$.

\section{Causative Agent}

Brucellosis is caused by infection with gram-negative bacilli of the genus Brucella. The genus encompasses nine recognized species including three species that are of economic importance ${ }^{[1,34]}$ and of which $B$. melitensis predominantly infects sheep and goat, $B$. abortus infects cattle, and $B$. suis infects swine ${ }^{[1]}$. These species may also infect camaloids, jacks and a variety of wildlife species. $B$. melitensis, B. abortus, and B. suis can be further subdivided in biovars, and further sub-species differentiation is possible using molecular tools.

\section{Global Situation}

Although some of the European and Asian countries have been declared free of Brucella, it is still widely prevalent ${ }^{[32,}$ ${ }^{35]}$. At present global burden of brucellosis is found to vary from 1 to 200 per 10 millions per year ${ }^{[35,36]}$. According to the available data, incidence of human brucellosis is economically feasible control option. It countries ${ }^{[37]}$. Moreover, it is endemic disease in Asian countries, such as Sri Lanka ${ }^{[38]}$, India ${ }^{[39]}$, China ${ }^{[40]}$, Pakistan ${ }^{[41]}$, Mongolia ${ }^{[42]}$, Nepal ${ }^{[43-45]}$. Despite some efforts to eradicatebrucella from animals, most have been terminated due to lack of sufficient funds ${ }^{[2,46]}$. Prevalence of both animal and human brucellosis is significant in rural nomadic communities of many countries, including Nepal. Nonetheless, the true incidence of human as well as animal brucellosis is still unknown for developing countries (including Nepal). This lower incidence of brucellosis in endemic areas, such as Nepal, denotes either the absence or low level of disease surveillance and monitoring.

\section{Nepalese Situation}

Regarding the literatures, there is a small number of published papers addresing the brucellosis. Most of the 
papers focused on bovine brucellosis with sparse information available to address brucellosis in humans and small ruminants. The available literatures indicate that bovine brucellosis in endemic in Nepal and B. abortus is the most predominant followed by B. suis. B. abortus is predominant in cattle accounting a substantial portion of bovine abortion in the country. Unfortunately, nothing has been done to identify the species of Brucella.

Though the brucellosis is reported to be endemic in Nepal, neither the distribution nor the economic and public health impact of this disease is well characterized ${ }^{[45,47]}$. This warrants a strong recommendation of better and 5057 serum samples of cattle, buffalo, is equally important to improve the present control programmes. A case where an university livestock farm got infected with Brucellosis because of an introduction of infected bulls imported from India is still fresh in our memories.

\section{Brucellosis in Animals}

The presence of brucellosis in Nepal was first established in 1977 by Pyakurel and Mishra ${ }^{[48]}$. Since then it has been reported from various parts of Nepal ${ }^{[49-54]}$ [Table1]. Pyakurel and Mishra ${ }^{[48]}$ studied the sero- epidemiology of brucellosis in animals within Nepal and reported the highest prevalence [22.64\%] in buffaloes from Pokhara. Joshi ${ }^{[49]}$ reported a prevalence of $6.08 \%$ in humans, $8.7 \%$ in cattle, and 3.64\% in sheep and goats. Department of Health Service (DHS) Nepal has reported that about $2-3 \%$ of cattles in Nepal are sero-positive for brucellosis. The published report, including the recent findings, clearly indicates that human and animal brucellosis is quite common in Nepal ${ }^{[45,48]}$. Brucellosis is found to be vary between different species of animals [17.6\% in Yak, Nak and Chauri, 10\% in dogs, 8.7\% in cattle and buffalo, $3.64 \%$ in sheep and goat, $7.18 \%$ in pigs] and also in terms of regions [1.49\% to $5.36 \%$ with highest number of cases found in Solukhumbu [5.36\%] and the lowest in Pokhara [1.49\%]. In another study carried out by Joshi 1983, brucellosis was found to be $6.08 \%$ in humans, $8.7 \%$ in cattle and $3.64 \%$ in sheep and goat. During the period of 2003-2013, the central veterinary laboratory ${ }^{[55]}$ tested between $5.6 \%-9.42 \%$, while in females sheep and goat that were suspected for brucellosis by RBPT, and reported a sero-positivity of $1.48 \%$; in contrast to these findings, the 1425 serum samples tested by indirect ELISA resulted in $0.35 \%$ seropositivity. Adhikari ${ }^{[56]}$ reported $2 \%$ sero-positivity in goats from Dang, with females having a higher percentage than males. In a recent study by Pandey et $a l^{[46]}, 32 \%$ of cattle, $13.4 \%$ of buffaloes, and $2.6 \%$ goats were found to be sero-positive. Brucellosis is endemic in nature and is ever increasing due to changes in the farming practice, increased movement and increased trade of animals ${ }^{[57]}$. As in correlation with Mantur and Amarnath ${ }^{[58]}$, the widespread use of bulls for the natural insemination might be the factor for endemicity of brucellosis in Nepal. Unlike India and other countries of the world, a religious taboo on the slaughtering of cattle is also contributing to the widespread distribution of brucellosis in animals in Nepal. In addition to this, the free grazing system and frequent mixing of animals of different species may also play a role in fostering a favorable environment for the spread of Brucella.

\section{Brucellosis in Humans}

Brucellosis is a significant public health problem in Nepal. The first human case was reported in 1979 when the disease was diagnosed in a shepherd from Pokhara by the isolation of $B$. melitensis, who most likely acquired the disease from his sheep. As recorded by various authors ${ }^{[64-66]}$, the incidence of brucellosis in Nepalese in males is it is between 2.9\% $6.60 \%$. Similarly, Joshi et al. ${ }^{[59]}$ repeated the research on human brucellosis, which was $4.48 \%$ in humans. Joshi et al. ${ }^{[57]}$ reported the occurrence of $1.4 \%$ in human, which is lower than the finding by Singh 1985, who reported $11.7 \%$ occurrence in workers of an abattoir in Kathmandu Valley [Table 2]. This higher incidence of brucellosis among slaughterhouse workers might be due to occupational exposure and poor hygiene of the slaughterhouses. Joshi et al 2007 reported the sero-prevalence of human brucellosis in Kathmandu to be $11.93 \%$, whereas Jackson et al, ${ }^{[45]}$ also reported a widespread sero-positivity of brucella in both humans and yak in Dolpa. In total, eighty-four cases of human brucellosis were confirmed from 1991 to $1997^{\text {[65] }}$ and one hundred and twelve confirmed positive cases of human brucellosis between 1997 and $2002^{[66]}$. Three major species of brucellosis (B. abortus, B. melitensis, and B. suis) have been reported to be present, although the precise distribution and prevalence of human brucellosis is still not available ${ }^{[66]}$. Although brucellosis is reportedly endemic in Nepal, neither the distribution nor the economic and public healthimpacts of the disease is well characterized ${ }^{[47]}$. In Nepal, approximately $90 \%$ of people live in villages and come into direct contact with domestic animals on a daily 
basis [48]; as a consequence, the local people of the villages are at a high risk of acquiring these types of zoonotic diseases ${ }^{[62,66]}$. Brucellosis has been found to vary by occupation [6.08-11.7\%]. The higher sero-positivity of males as compared to the females might be due to the close contact of men with animals, the dynamic nature, and higher mobility than females ${ }^{[66]}$. The overall prevalence of brucellosis was 110 cases $/ 10^{5}$ inhabitants, which decreased to less than 20 cases $/ 10^{5}$ inhabitants from 2003 onwards ${ }^{[67]}$. This reduction in reported cases of brucellosis from 2003 onwards might be either due to a lack of disease surveillance, resulting from the under-reporting of the disease in Nepal or an increased awareness among veterinary practitioners and farmers. This higher prevalence of human and animal brucellosis is alarming and significant for animals and public health in Nepal.

Table 2. Occurrence of Brucellosis in humans of Nepal

\begin{tabular}{|c|c|c|c|c|c|}
\hline Location & Patient types & $\begin{array}{l}\text { Test } \\
\text { employed }\end{array}$ & \% Prev & ence & References \\
\hline \multirow[t]{2}{*}{ Kathmandu } & $\begin{array}{l}\text { Indoor and } \\
\text { outdoor } \\
\text { patients }\end{array}$ & РАT,SAT, 2ME & $57 / 2117$ & $2.7 \%$ & $\begin{array}{l}\text { Joshi et al } \\
\text { [64] }\end{array}$ \\
\hline & $\begin{array}{l}\text { Patients } \\
\text { admitted to } \\
\text { Bir Hospital }\end{array}$ & Card test & $28 / 200$ & $14 \%$ & Rana [44] \\
\hline Kathmandu & & Card test & $87 / 1430$ & $6.08 \%$ & Joshi [49] \\
\hline \multirow[t]{3}{*}{ Kathmandu } & $\begin{array}{l}\text { Humans of } \\
\text { Kathmandu } \\
\text { valley }\end{array}$ & Plate test & $3 / 121$ & $2.47 \%$ & $\begin{array}{l}\text { Pyakurel and } \\
\text { Mishra [48] }\end{array}$ \\
\hline & $\begin{array}{l}\text { General } \\
\text { population }\end{array}$ & PAT & $3 / 5000$ & $0.06 \%$ & $\begin{array}{l}\text { Singh et al } \\
\text { [62] }\end{array}$ \\
\hline & & PAT & $120 / 1006$ & $11.9 \%$ & $\begin{array}{l}\text { Joshi et al } \\
{[66]}\end{array}$ \\
\hline \multirow[t]{3}{*}{ Pokhara } & $\begin{array}{l}\text { Patients } \\
\text { showing the } \\
\text { one or more } \\
\text { symptoms of } \\
\text { brucellosis }\end{array}$ & PAT & $25 / 558$ & $4.48 \%$ & Joshi [57] \\
\hline & & PAT & $123 / 1506$ & $8.17 \%$ & $\begin{array}{l}\text { Joshi et al } \\
\text { [66] }\end{array}$ \\
\hline & $\begin{array}{l}\text { Sheep } \\
\text { shepherd }\end{array}$ & PAT, ELISA & 1 case & $\cdots-\cdots$ & $\begin{array}{l}\text { Dickenson } \\
\text { and Thaller } \\
\text { [68] }\end{array}$ \\
\hline
\end{tabular}




\section{Clinical Symptoms}

The clinical presentation is non- specific and requires laboratory testing for confirmation. Common presentations (fever, nausea, anorexia, headache, sweating, prostration etc coupled with gastro-intestinal, musculoskeletal, hepatobiliary and meningeo-vascular complications are common

${ }^{[32]}$. Fever is the most common manifestation followed by the arthritis, sweating and constitutional symptoms ${ }^{[35,69-71]}$. It may appear in acute, with an incubation period of 2-3 weeks or sub-acute or chronic cases with an incubation period of weeks to months.

\section{Diagnosis}

Brucellosis is an intra-cellular pathogen in cells of the immune system and therefore difficult to diagnose and treat. Definitive diagnosis requires the isolation of the organism from the patient, but is restricted by the fact that Brucella spp. are slow-growing intracellular pathogens, whose successful culture from blood decreases as the disease progresses ${ }^{[72,73]}$. Previous use of antibiotics also adds to the difficulty of culturing the bacillus ${ }^{[74]}$. As such, successful diagnosis necessitates a careful selection of the best suitable culture method and validation of its performance. The sensitivity of culturing Brucella spp. from blood varies from $15 \%$ to $70 \%$ when compared with clinical evidence of infection and positive serologic results depending on the study and culture method used ${ }^{[73]}$. Culture provides direct evidence of the presence of the pathogen and is the gold standard, but in the absence of adequate culture facilities, brucellosis might be diagnosed by serologic testing. A variety of serological tests including the Rose Bengal screening test, SAT, 2-ME, Coombs and ELISA etc are available for the sero-doagnosis of human brucellosis. Most of the serological tests are highly sensitive but they arenot highly specific. Different types of gram negative bacteria such as Escherichia coli, Vibrio cholera, Escherichia hermanni, Salmonella, Francisella tularensis, etc., elicit antibody response that cross react with Brucella antigen thus low specificity of serological tests. Though the modern diagnostic techniques with high sensitivity and specificity such as Polymerase Chain Reaction (PCR) have been introduced, they arenot widely used in field condition and in developing countries.

Diagnosis of brucellosis in field condition relies heavily on serological tests. However, specificity of such tests have been a major cause of concern. Although there are several serological tests such as the agglutination, antigen detection and antibody detection, none of the tests are $100 \%$ reliable, so these test results, should be supplemented with the case history, clinical manifestation and other laboratory findings ${ }^{[75-77]}$. Serological tests should always be interpreted along with the patient history, clinical findings and laboratory findings. At least two serological tests should be used to confirm active infection in animals.

The Rose Bengal Plate test (RBPT) is the most commonly used agglutination test in diagnosis of brucellosis in field condition where there is no possibility to perform SAT. The result of RBPT should always be confirmed by other tests due to its low sensitivity in chronic cases and low specificity in endemic areas ${ }^{[78]}$.

The SAT is the gold standard assay ${ }^{[79.82]}$. Generally SAT is used first followed by the 2-mercaptoethanol (2ME) test to confirm the result of SAT by excluding the possibility of cross reacting Ig M. Sometimes the result of $2 \mathrm{ME}$ can be mis-interpreted in patients with low levels of $\operatorname{IgG}^{[83]}$.

Specific IgM ELISA antibodies are useful in diagnosis of acute brucellosis ${ }^{[7,84]}$ whereas the Coombs test and $\operatorname{IgG}$ ELISA are useful in the detection of chronic infection and monitoring of relapsing strains due to their abilities to detect incomplete antibodies ${ }^{[84]}$. However, dipstick test can be used in patients as a rapid and simple alternative to ELISA IgM test for the serodiagnosis of patients with acute brucellosis ${ }^{[85,86]}$. For accurate diagnosis of a suspected case, combination of ELISA IgM and IgG tests with follow-up and monitoring by ELISA IgM and 2-MET might be helpful due to the their promising efficiency ${ }^{[8]}$. In addition, Fluorescence polarization assay [FPA] and immunocapture agglutination for anti-Brucella $[\mathrm{BCAP}]$ might be alternative choice due to their ability to detect the disease in patients with longstanding evolution of brucellosis. Brucella IgM and IgG lateral flow ${ }^{[75]}$ and latex agglutination ${ }^{[8,89]}$ assays have also been found to be rapid and simple along with high sensitivity and specificity in culture of confirmed cases that are useful for the field condition in remote areas where other methods may not be feasible.

Although the gold standard is isolation of Brucella organism from the blood and bone marrow culture, PCR based testing method is a more accurate method for testing the presence of Brucella, promising to be more useful and practical ${ }^{[90]}$. PCR is particularly useful in patients with specific complications such as neurobacillosis or other 
localized conditions where serological tests fail to address them ${ }^{[1,92]}$ however the sensitivity, specificity and quality control is a matter of concern ${ }^{[3,93,94]}$. By correcting the drawbacks of conventional PCR, real time PCR has been developed that is less prone to contamination, faster and clinically more useful ${ }^{[95,96]}$. However, expensive nature of the real time PCR has restricted its use in the field condition and in developing countries.

In short, presumptive diagnosis of brucellosis should be based on patient history and clinical findings. These clinical findings should be combined with the Rose Bengal plate test (RBPT) or SAT, and positive reactors to be confirmed by additional confirmatory tests. Positive ones based on the detection of agglutinating antibodies (RBPT, SAT) should be combined with the detection of non-agglutinating antibodies through tests such as ELISA or Coomb's test.

\section{Treatment of Brucellosis}

Treatment of brucellosis in animals isnot effective and infected animal is to be isolated such that further transmission doesnot occur. If feasible, the infected animals should be destroyed and properly disposed. Multi drugs regimens are to be followed for therapy because of high relapse rate reported with monotherapeutic approaches ${ }^{[71,97,98]}$. Treatment failure and relapse rates can be high and depend on the drug combination and compliance ${ }^{[7]}$. Despite the several studies on antibiotics for the management of brucellosis, no conclusive evidence for optimum antibiotics therapy have been reported so far ${ }^{[71,98]}$. The treatment for acute brucellosis recommended by the world health organization (WHO) is doxycycline @ 100 mg two times a day (BID) orally and rifampin 600 to $900 \mathrm{mg} /$ day per oral (PO) for 6 weeks ${ }^{[99]}$, but this regimen is not to be followed in complicated cases such as the spondylitis and tuberculosis patients ${ }^{[100,101]}$ owing to the possibility of resistant Mycobacterium tuberculosis. Rifampin mono-therapy is the major choice for treating brucellosis during pregnancy and combination of sulphamethoxazole- trimethoprim for brucellosis in children ${ }^{[102]}$. Clinical trials with other antibiotics such as quinolones, macrolides, sulphatrimethoprim, cotrimoxazole and rifampin have resulted the poor results.

Some of the localized form of brucellosis such as endocarditis, meningitis, spondylitis shouldbe dealt with surgery supplemented by the triple antibiotics therapy (Doxycycline, Rifampicin, and Trimethoprim- sulfamethoxazole ${ }^{[103]}$. What we have to consider here is that the antibiotic regimen has to be selected based on the underlying conditions and the location of the disease.

\section{Control}

Brucellosis may be controlled by the strict enforcement of a set of measures including test and slaughter, vaccination, sanitation, and movement control ${ }^{[32]}$. However, the control of brucellosis has proven to be cumbersome and in Hinduism countries the control of bovine brucellosis is limited as the slaughtering of cattle is prohibited. Knowledge of the distribution and spread of brucellosis and their presence in the different livestock and wildlife species is essential for the effective implementation of control measures. A few serological studies have investigated the presence and distribution of brucellosis in livestock and human in Nepal and the risk of transmission to the human population.

Lack of awareness among the farmers, and limited vaccine availability has made the situation favorable for the endemicity of brucellosis in Nepal.Thus, animal owners should be made aware about the economic impact, health impact and importance of vaccination of their livestock. Public health education should emphasize on food hygiene and occupational hygiene. Avoiding or discouraging using raw milk and dairy products, a strict procedure of protective and safety measures of health workers will help prevent brucellosis in human population.

\section{Recommendations}

Some of the recommendations for prevention of brucellosis in Nepal are as follows:

\section{Increase in public awareness by awareness campaign:}

Efforts should be made by the government and the concerned sector for raising awareness of the disease and its impact on public health. The first weapon of disease prevention is minimization of exposure, which can be achieved by the educating the high risk groups including farmers and others from similar occupational category. Clothes and other protective measures should be followed during handling of animals. Training should be provided for the farmers and livestock attendants for effective sanitary and hygienic management practices during handling of animals and animal products such as aborted fetus and other body secretions. Thus, in underdeveloped countries like Nepal, where eradication in animals (through the mass 
vaccination and/or elimination of infected animals) is not feasible, prevention of human infection should be based on public awareness, food safety measures, laboratory safety and occupational hygiene.

\section{Food hygiene:}

Since Brucella is readily killed by heat treatment, boiling of milk and heating of milk products at 80-85 degree centigrade will kill these bacteria and makes milk safe for human consumption. The feeding habits of raw and uncooked meat and milk need to be understood in its complete sense similar to the methods of preparation and addition of spice and herbs. Likewise, cultural practices such as direct milk drinking from the udder, uncooked cow's milk and urine mixed together to make elixir should be carefully studied for any chances of creating infection. In Nepal, we have practice like drinking raw blood from standing yak and, health concerns of such practices have to be established before we advocate its modification.

\section{Control of brucellosis in animals by regular surveillance, screening and immunization:}

Regular surveillance is necessary as it is one of the important steps for preventive and control measures. Cost effective surveillance method includes regular testing of bulk quantities of milk ${ }^{[104]}$ and RBPT as well as the PAT test to screen for positive animals. Although the MRT is not an effective test for testing the milk of sheep and goats due to fatty nature, other alternatives such as the RBPT and PAT can be used effectively ${ }^{[105]}$. Strict implementation of quarantine and sero-surveillance is an utmost necessity ${ }^{[106,107]}$. Detailed epidemiological investigation of the three pillars of the disease should be conducted across the country to identify the associated risk factors for the occurrence and endemicity of the disease. Immunization of animals with vaccines is the utmost need for prevention and control. Rev1, a modified live virus vaccine can be used in small ruminants at three to four months of age providing immunity for three to five years ${ }^{[108,109]}$. Strain 19 and RB51 are commonly used for the prevention of brucellosis in cattle. These vaccines are used to vaccinate calves between four to twelve months. The latter has better advantages due to the less abortogenic character and non complexity of immunity induced by RB51, in which the infected animal's serology can be easily separated from the vaccinated ones ${ }^{[110]}$. The vaccination of cattle with RB51 is an important choice for the prevention, control and eradication of brucellosis ${ }^{[104,111-114]}$.

\section{Maintaining healthy contact with animals:}

Since the sharing of water points for drinking and grazing lands are important risk factors for transmission of brucellosis, avoiding the mixing of cattle and other animals as well as raising a replacement heifer within a herd might be an important step for control and prevention of brucellosis in humans and animals. Screening of animals before purchasing and entering them into a herd, proper disposal of aborted materials and isolation of animals in parturition help to reduce the transmission of brucellosis across the herd ${ }^{[111]}$.

\section{Testing and slaughtering of infected animals:}

If the regular vaccination of animals against brucellosis is not practiced then the test and slaughter method can be used as the cost effective measures ${ }^{[7,108]}$. For the under-developed countries like Nepal, the test and slaughter method is difficult due to the cost involved in the slaughter of animals ${ }^{[112,115,116]}$ and the religious taboo existing in the country. The control of disease in animals in Nepal should depend first on the mass vaccination of all animals for few years till the incidence of infection decline up to $1 \%$, and only then one can count on the test and slaughter of infected animals, as it will be non- expensive. Therefore, full cooperation of government and other stakeholders is necessary for this method to be successful.

\section{CONCLUSION}

Like other underdeveloped and developing countries of world, the situation of brucellosis is alarmingly serious herein Nepal. There is a urgent need of extensive research on epidemiolical picture and public health impacts. Control of brucellosis in animals and reducing transmission to humans should be instigated. Vaccination and awareness program should be strengthened by veterinary and paraveterinary services.

\section{REFERENCES}

1. Corbel MJ.Brucellosis in humans and animals. Geneva (Switzerland): World Health Organisation; 2006.

2. McDermott JJ, Arimi SM. Brucellosis in sub-Saharan Africa: epidemiology, control and impact.Vet Microbiol2002; 90: 111134 [PubMed]

3. Nimri LF. Diagnosis of recent and relapsed cases of human brucellosis by PCR assay. BMC Infect Dis 2003;3:5. 
4. Cutler SJ, Whatmore AM, Commander NJ. Brucellosis new aspects of an old disease. J Appl Microbiol 2005; 98:1270-1281.

5. Smits HL, Kadri SM. A deceptive infectious disease. Ind JMed Res 2005; 122: 375-84.

6. Schelling E, Diguimbaye C, Daoud S, Nicolet J, Boerlin $\mathrm{P}$ et al. Brucellosis and Q-fever seroprevalences of nomadic pastoralists and their livestock in Chad. Preventive Veterinary Medicine 2003; 4(61): 279-293.

7. Refai M. Incidence and control of brucellosis in the Near East region. Vet Microbiol 2002; 90: 81-100.

8. Agasthya AS, Isloor S, Prabhudas K.Brucellosis in high risk group individuals. Indian J Med Microbiol. 2007;25(1):28-31.

9. Mohamed E, Mona S. Sero- prevalence of brucellosis among abattoir house and butcher shops' workers in Assiut City, SCVMJ, XVIII,2013; (2):5567.

10. Jones BA, Grace D, Kock R, Alonso S, Rushton J, et al. Zoonosis emergence linked to agricultural intensification and environmental change. Proc Natl Acad Sci USA 2013; 110: 83998404.

11. Neilson, Duncan. Animal Brucellosis CRS press, Inc 2000, Blvd corporate, N.W. Boca Raton Florida 1990: 33431.

12. Abubakar M, Arshed MJ, Hussain M, EhtishamulHaq, Ali Q. Serological evidence of Brucella abortus prevalence in Punjab province, Pakistana crosssectional study. Transbound Emerg Dis 2010; 57(6):443447

13. Nikokar I, Hosseinpour M, Asmar M, Pirmohbatei S, Hakeimei F, and Razavei MT.Seroprevalence of Brucellosisamong high risk individuals in Guilan, Iran. J Res Med Sci.2011;16(10):1366-1371.

14. Bataineh H. Clinical study of childhood brucellosis in Jordan. Mid East J Fam Med.2007; 5(3): 135-8.

15. Kato Y, Masuda G, Itoda I, Imamura A, Ajisawa A, Negishi M. Brucellosis in a 372 melitensis. J travel med2007;14:343-345.

16. Shang D, Donglou X, Jiming Y. Epidemiology and control of brucellosis in China. Vet Micro.2002; 90: 165-182.

17. Pappas G, Bosilkovski M, Akritidis N, Mastora M,
Krteva L and Tsianos E 2003 Brucellosis and the respiratory system; Clin. Infect. Dis. 37 e95e99.

18. Muma JB, Samui K L, Siamudaala VM, Oloya J, Matope G, Omer MK, Munyeme M, Mubita C and Skjerve E. Prevalence of antibodies to Brucella spp. and individual risk factors of infection in traditional cattle, goats and sheep reared in livestock wildlife interface areas of Zambia. Trop Anim Hlth Prod 2006; 38: 195206 .

19. Matope G, Bhebhe E, Muma JB, and Lund A, Skjerve E. Herd-level factors for Brucella seropositivity in cattle reared in smallholder dairy farms of Zimbabwe. Prev Vet Med 2010; 94: 213221.

20. Olsen S, Tatum F. Bovine brucellosis. Vet Clin North Am Food Anim Pract 2010; 26: 15-386

21. Ducrotoy MJ, Bertu WJ, Ocholi RA, Gusi AM, Bryssinckx W, et al. Brucellosis as an Emerging Threat in Developing Economies: Lessons from Nigeria. PLoS Negl Trop Dis 2014; 8(7): e3008

22. Mantur BG, Mangalgi SS, Mulimani B. Brucella melitensisa sexually transmissible agent. Lancet 1996; 347:1763.

23. Erten M, Kurekci AE,AysevD, Unal E, Ikinciogullari A. Brucellosis transmitted by bone marrow transplantation. Bone marrow transplant. 2000;26:225 $-226$.

24. Arenas GN, Staskevich AS, Aballay A, Mayorga LS. Intracellular trafficking of Brucella abortus in $\mathrm{J774}$ macrophages. Infect. Immun. 2000;68:4255-4263.

25. Boschiroli ML, Ouahrani-Bettache S, Foulongne V, Michaux-Charachon S, Bourg G, Allardet-

26. Bricker BJ. PCR as a diagnostic tool for brucellosis. Vet Microbiol 2002; 90: 43546.

27. Alavi SM, Motlagh ME. A Review of Epidemiology Diagnosis and Management of Brucellosis for General Physicians Working in the Iranian Health Network. Jundishapur J Microbiol. 2012; 5:3847.

28. Jonne DB. Infections and perinatal diseases a comparative overview. Acta Veterinaria Scandinavica. 2007, 49 (Suppl 1):S10 doi:10.1186/1751- 0147-49$\mathrm{S} 1-\mathrm{S} 10$

29. Rodríguez MC, Viadas C, Seoane A, Sangari FJ, López-Goñi I, et al. Evaluation of the Effects of Erythritol on Gene Expression in Brucella abortus. 
PLoS ONE 2012; 7(12): e50876.

30. Enright FM. The pathogenesis and pathobiology of Brucella infection in domestic animals. In Animal brucellosis (K. Nielsen \& R. Duncan, eds). CRC Press, Boca Raton, Florida.1990; 301320.

31. Gilbert P, Holst F, Rossbach J, Pauli HK. Brucellosisinduced granulomatous non-puerperal mastitis-a case report. Geburtsilfe Frauenheilkund 1991; 51:747-9.

32. Pappas G, Papadimitriou P, Akritidis N, Christou L, and Tsianos EV. The new global map of human brucellosis. Lancet Infect Dis 2006; 6:91-99.

33. Young EJ. Brucella species. In: Mandell GL, Douglas RG, Bennett JE. Principles and practice of infectious diseases. Churchill Livingstone: Wiley; 2005: 26692674.

34. McDonald WL, Jamaludin R, Mackereth G, Hansen M, Humphrey S, Short P, Taylor T, Swingler J, Dawson CE, Whatmore AM, Stubberfield E, Perrett LL, Simmons G. Characterization of a Brucella sp. strain as a marine-mammal type despite isolation from a patient with spinal osteomyelitis in New Zealand. J Clin Microbiol 2006; 44:43634370. 10.1128/JCM.0068006

35. Dean AS, Crump L, Greter H, Hattendorf J, Schelling E, et al. Clinical manifestations of human brucellosis: a systematic review and meta-analysis. PLOS Negl Trop Dis. 2012; 6: 1929.

36. Markos M, Anastasios M, Konstantinos G, Athanasia S. Epidemiological and Clinical Aspects of Human Brucellosis in Central Greece, Jpn. J. Infect. Dis. 2007; $60(6): 362-366$.

37. Hegazy YM, Ridler AL, Guitian FJ. Assessment and simulation of the implementation of brucellosis control programme in an endemic area of the Middle East. Epidemiol Infect. 2009; 137(10):1436-1448.

38. Priyantha MAR. Identification of Biovars of Brucella Abortus in Aborted Cattle and Buffaloes Herd in Sri Lanka. Vet. World, 2011;4(12):542-545.

39. Ghodasara SN, Roy A, Bhanderi BB. Comparison of Rose Bengal Plate Agglutination, Standard Tube Agglutination and Indirect Elisa Tests for Detection of Brucella Antibodies in Cows and Buffaloes. Veterinary World, 2010; 3(2):61-64.

40. Deqiu S, Donglou X, Jiming Y. Epidemiology and
Control of Brucellosis in China. Veterinary Microbiology 2002;90(14):165-182.

41. Akhtar R, Chaudhry PZI, Shakoori PAR, A h m a d MUD, Aslam A. Comparative Efficacy of Conventional Diagnostic Methods and Evaluation of Polymerase Chain Reaction for the Diagnosis of Bovine Brucellosis. Veterinary World. 2010; 3(2):5356

42. Zinnstag J, Roth F, Orkhon D, Chimed-Ochir G, Nansalmaa M, Kolar J, Vounatsou P. A model of animal human brucellosis transmission in Mongolia. Prev Vet Med. 2005; 69, 7795.

43. Knox C, Gillies L, Joshi DD. Veterinary public health in the NepalHimalaya. The Canadian Veterinary Journal,2000; 41:879881.

44. Rana HB. Sero-epidemiological surveillance of Human and Animal Brucellosis in Surkhet District, Mid- western Region of Nepal. M. Sc. Zoology Thesis, TU, Nepal 2002: 25.

45. Jackson DS, Nydam DV, Altier C. Prevalence and risk factors for brucellosis in domestic yak Bos grunniens and their herders in a transhumant pastoralist system of Dolpo, Nepal, Preven Vet Med. 2014; 113(1) : 47-58.

46. Pandeya YR, Joshi DD, Dhakal S, et al. Seroprevalence of brucellosis in different animal species of Kailali district, Nepal. Int J Infect Microbial 2013;2(1);22-25.

47. Aryal S, Poudel KP. Reproductive Disorders and Seroprevalence of Brucellosis in Yak. Nepal Agric. Res. J. 2007;8:130-132

48. Pyakyurel S, Mishra U. Sero- Epidemiological Evidence of Animal Brucellosis in Nepal, Bull Veterinary Science \& Animal Husbandry, Nepal. 1977: $6: 1-6$.

49. Joshi DD. A Public Health problem in Nepal. Bulletin of Veterinary Science and Animal Husbandry Nepal. 1983;12:15-16.

50. Joshi DD, Maharjan M. Urban Ecosystems and Health in Kathmandu: Community Based Biological Assessment of Drinking Water sources in: Martin J. B, V. M. Suresh and T.V. Kumarnan, eds., Proceedings of the Third International Conference on Environment and Health, Chennai, India. 15-17 December 2003. Chennai: Department of Geography, University of Madras and Faculty of Environmental Studies, York 
University, Pp 186-195.

51. Pradhan A. Sero-surveillance of brucellosis in cattle and buffaloes in Chitwan. In: Proceedings of First National Livestock and Fisheries Research Workshop. 1996; 227-231.

52. Rana S. Seroprevalence of Brucellosis in Slaughter Swine in the Kathmandu valley. B.V.Sc \& AH internship report IAAS, T.U. Nepal. 2005.

53. Paudel A. Seroprevalence of Brucellosis in Small ruminants in Nepal. B.V.Sc \& AH internship report IAAS, T.U. Nepal. 2006.

54. Lefkowitz NA, Joshi DD, Chhetri DB, Sharma M. Prevalence of Brucellosis in Yaks and Other Cattle of Langtang Valley. Nepalese Vet. J. 2003; 27: 12-17.

55. CVL (VEC). Annual Epidemiological Bulletin-2005, (Jan. Dec.). Veterinary Epidemiology Center, Directorate of Animal Health, Tripureswor.2012; 120 122.

56. Adhikari S. Prevalence of brucellosis in goats of Dang districts, Nepal Souenir 2012. 10th national veterinary conference, Kathmandu, Nepal, 2012.

57. Joshi DD. Epidemiological Surveillance of Human and Animal Brucellosis in Milk collection area of DDC, Nepal. NZFHR. 2000.

58. Mantur BG, Amarnath SK. Brucellosis in India-a review. J Biosci 2008; 33: 539-547.

59. Joshi DD. Status of Brucellosis in Man and Animals in Nepal, WHO/SEARO. India Publication, New Delhi. 1992.

60. Joshi DD, Upadhya M, Mishra PN.Brucellosis in Animal and Human of Chitwan NZFHRC Tahachal.2005; 37-48.

61. Dhakal IP, Jost C, Joshi DD. Training on livestock and poultry derived food safety and hygiene in four communities in Chitwan district, The Blue cross Annual Bulletin, NVSA, 2005(7):8-14.

62. Singh HL. Principal Records of Nepal. 1985;2:45-62.

63. Shrestha B. Sero-prevalence of Brucellosis in different species of meat animals of Nepal. B.V.Sc \& AH internship report. IAAS, T.U. Nepal.2008.

64. Joshi DD. Incidence of Human Brucellosis in Kathmandu. JNMA. 1984;22 (2): 1-7

65. Joshi DD. Status of Brucellosis in Man and Animals in
Nepal, WHO/SEARO. India Publication, New Delhi. 1992.

66. Joshi DD, Shrestha IL, Aryal A. Veterinary and Human Public Health Importance of Brucellosis in Nepa. Nepal veterinary journal. 2007:29: 77-81.

67. GIDEON informatics, Infectious diseases of Nepal, 2014, Pp: 44, www.gideononline.com

68. Dickenson JG, Thaller VT. Brucellosis in shepherds in Nepal. J Nep Med Assoc. 1979, 17(1):20-24.

69. Bukharie HA. Clinical Features, Complications and Treatment Outcome of Brucella infection: Ten Years' Experience in an Endemic Area. Trop J Pharm Res. 2009; $8(4): 303$.

70. Mantur BG, Akki AS, Mangalgi SS, Patil SV, Gobbur RH, Peerapur BV. Childhood brucellosis - a microbiological, epidemiological and clinical study. J Trop Pediatr 2004; $50: 1537$.

71. Matthew E. Falagas, Ioannis AB. Quinolones for Treatment of Human Brucellosis: Critical Review of the Evidence from Microbiological and Clinical Studies. Antimicrob. Agents Chemother. 2006; (50):122-233.

72. Iseri S, Bulut C, Yetkin MA, Kinikli S, Demiroz AP, et al. (2006) Comparison of the diagnostic value of blood and bone marrow cultures in brucellosis. Mikrobiyol Bul 40: 201-206.

73. Aliskan H. The value of culture and serological methods in the diagnosis of human brucellosis. Mikrobiyol Bul.2008;42(1):185-95.

74. Al Tawfiq JA, Abu Khamsin A. A 24- year study of the epidemiology of human brucellosis in a health-care system in Eastern Saudi Arabia. J Infect Public Health,2009;2: 818.

75. Smits H L, Abdoel T H, Solera J, Clavijo E, Diaz R. Immunochromatographic Brucella- specifi c immunoglobulin $\mathrm{M}$ and $\mathrm{G}$ lateral $\mathrm{fl}$ ow assays for rapid serodiagnosis of human brucellosis; Clin. Diagn. Lab. Immunol.2003; 10:11411146

76. Ozdemir M, Feyzioglu B, Kurtoglu MG, Dogan M, Dagi HT, et al. A comparison of immunocapture agglutination and ELISA methods in serological diagnosis of brucellosis. Int J Med Sci 2011; 8: 428432.

77. Fadeel MA, Hoffmaster AR, Shi J, Pimentel G, 
Stoddard RA. Comparison of four commercial IgM and IgG ELISA kits for diagnosing brucellosis. J Med Microbiol. 2011;60: 1767-1773.

78. Mantur BG, Biradar MS, Bidri RC, Mulimani MS, Veerappa, Kariholu, P, Patil SB, Mangalgi SS. Protean clinical manifestations anddiagnostic challenges of human brucellosis in adults: 16 years' experience in endemic area. J. Med. Microbiol.2006; 55:897903.

79. El Sherbini A, Kabbash I, Schelling E, El Shennawy S, Shalapy N, et al. Seroprevalences and local variation of human and livestock brucellosis in two villages in Gharbia governorate, Egypt. Trans R Soc Trop Med Hyg. 2007; 101: 923928.

80. Doyle TJ, Bryan RT. Infectious disease morbidity in the US regionbordering Mexico, 19901998. J Infect Dis. 2000; 182: 15031510.

81. Supriya C, Umapathy BL, Ravikumar KL. Brucellosis: review on the recent trends in pathogenicity and laboratory diagnosis. J Lab Physicians. 2010; 2: 55-60.

82. Araj GF. Update on laboratory diagnosis of human brucellosis. Int J Antimicrob Agents. 2010; 36: 12-17.

83. Mantur B, ParandeA, Amarnath S, Patil G, Walvekar R, et al. ELISA versus conventional methods of diagnosing endemic brucellosis. Am J Trop Med Hyg. 2010; 83:314318.

84. Pabuccuoglu O, Ecemis T, El S, Coskun A, Akcali S, et al. Evaluation of serological tests for diagnosis of brucellosis. Jpn J Infect Dis. 2011; 64: 272-276.

85. Lim ML, Richman LS. Brucellosis. Infect Dis Clin Pract. 2004; 12: 7-14

86. Taleski V. An overview of introducing various laboratory tests for diagnosis of human brucellosis in the republic of Macedonia. Maced J Med Sci. 2010; 3: 239-245.

87. Asaad AM, Alqahtani JM. Serological and molecular diagnosis of human brucellosis in Najran, Southwestern Saudi Arabia. J Infect Public Health. 2012; 5: 189-194.

88. Yu WL, Nielsen K. Review of detection of Brucella spp. by polymerase chain reaction. Croat Microbiol J. 2010; 51:306-313.

89. Colmenero JD, Queipo-Ortuno MI, Reguera JM, et al. Real time polymerase chain reaction: a new powerful tool for the diagnosis of neurobrucellosis. J Neurol
Neurosurg Psychiatry 2005; 76: 102527.

90. Yu WL, Nielsen K. Review of detection of Brucella spp. by polymerase chain reaction. Croat Microbiol J. 2010; 51:306-313.

91. Colmenero JD, Queipo-Ortuno MI, Reguera JM, et al. Real time polymerase chain reaction: a new powerful tool for the diagnosis of neurobrucellosis. J Neurol Neurosurg Psychiatry 2005; 76: 102527.

92. Newby DT, Hadfi eld TL, Roberto FF. Real-time PCR detection of Brucella abortus: a comparative study of SYBR green I, 5'- exonuclease, and hybridization probe assays. Appl Environ Microbiol 2003; 69: 475359.

93. Khosravi AD, Abassi E, Alavi SM. Isolation of Brucella melitensis and Brucella abortus from brucellosis patients by conventional culture method and polymerase chain reaction technique. Pak J Med Sci 2006; 22(4):396-400.

94. Gemechu MY, Gill JPS, Arora AK, Ghatak S, Singh DK.Polymerase chain reaction (PCR) assay for rapid diagnosis and its role in prevention of human brucellosis in Punjab, India. Int J Prev Med. 2011; 2: 170- 177.

95. Probert WS, Schrader KN, Khuong NY, Bystrom SL, Graves MH. Real- time multiplex PCR assay for detection of Brucella spp, B abortus, and B melitensis. J Clin Microbiol 2004; 42: 129093.

96. Debeaumont C, Falconnet PA, Maurin M. Real-time PCR for detection of Brucella spp DNA in human serum samples. Eur J Clin Microbiol Infect Dis 2005; 24: 84245 .

97. Roushan MR, Gangi SM, Ahmadi SA. Comparison of the efficacy of two months of treatment with cotrimoxazole plus doxycycline vs. co- trimoxazole plus rifampin in brucellosis. Swiss Med Wkly. 2004; 134(37-38):564-8.

98. Al-Anazi KA, Al-Jasser AM. Brucellosis: A Global Reemerging Zoonosis; Diagnosis, Treatment and Prevention. OMICS group ebooks. 2014. http://esciencecentral.org/ebooks/ bacterial-mycoticinfections/ brucellosis-2.php

99. Alp E, Koc RK, Durak AC, Yildiz O, Aygen B, et al 2006. Doxycycline plus streptomycin versus ciprofloxacin plus rifampicin in spinal brucellosis 
[ISRCTN3 1053647]. BMC Infect Dis 6: 72.

100.Ariza J, Bosilkovski M, Cascio A, Colmenero JD, Corbel MJ, Falagas ME, et al. Perspectives for the treatment of brucellosis in the 21st century: the Ioannina recommendations. PLoS Med. 2007; 4(12):e317. [DOI: 10.1371/journal.pmed.0040317]

101. Skalsky K, Yahav D, Bishara J, Pitlik S, Leibovici L, Paul M. Treatment of human brucellosis: systematic review and meta- analysis of randomised controlled trials. BMJ. 2008;336 (7646):701-4. [DOI: 10.1136/bmj.39497.500903.25]

102.Khuri-Bulos NA, Daoud AH, Azab SM. Treatment of childhood brucellosis: results of a prospective trial on 113 children. Pediatr. Infect. Dis. J. 1993; 12:377-381. Yilmaz E, Parlak M, Akalin H, Heper Y,Ozakin C, Mistik R, Oral S, Helvaci S, Tore O. Brucellar spondylitis. Review of 25 cases. J.

103. McLean D R, Russell N, Khan MY. Neurobrucellosis: clinical and therapeutic features; Clin. Infect. Dis.1992; 15: 582590

104.Alavi S, Rajabzadeh A. Comparison of two chemotherapy regimen: Doxycycline-rifampicin and doxycycline cotrimoxazol in the brucellosis patients Ahwaz, Iran, 2004-2006. Pakistan J Med Sci 2007; 23(6):889.

105.Ersoy Y, Sonmez E, Tevfik MR, But AD. Comparison of three different combination therapies in the treatment of human brucellosis. Trop Doct 2005; $35: 210-12$.

106.Karabay O, Sencan I, Kayas D, Sahin I. Ofloxacin plus rifampicin versus doxycycline plus rifampicin in the treatment of brucellosis: a randomized clinical trial [ISRCTN11871179]. BMC Infect Dis. 2004; 4:18.

107.Ragan VE. The Animal and (APHIS) brucellosis eradication program in the United States. Vet. Microbiol 2002; 90, 1118.
108.Plant Health Inspection Service

109.MacMillan A. Animal brucellosis. In: Nielsen, K., Duncan, J.R. (Eds.), Conventional Serological Tests. CRC Press, Inc., Boca Raton, FL 1990; 153197.

110. Russo G, Pasquali P, Nenova R, Alexandrov T, Ralchev $\mathrm{S}$, et al. Reemergence of human and animal brucellosis, Bulgaria. Emerg Infect Dis 2009; 15: 314-316.

111. Hotez PJ, Savioli L, Fenwick A. Neglected tropical diseases of the Middle East and North Africa: review of their prevalence, distribution and opportunities for control. PLoS Negl Trop Dis 2012; 6:1475.

112. Blasco JM, Molina-Flores B. Control and eradication of Brucella melitensis in sheep and goats. Vet. Clin. North Am. Food Anim. Pract 2011; 27, 95104

113. Olsen SC, Stoffregen WS. Essential role of vaccines in brucellosis control and eradication programs for livestock. Expert Rev. Vaccines 2005; 4: 915928

114. Vemulapalli R, He Y, Sriranganathan N, Boyle SM, Schurig GG. Brucella abortus RB51: enhancing vaccine efficacy and developing multivalent vaccines. Vet Microbiol 2002; 90, 521532

115. Rivera AS, Ramirez CM, Lopetegui PI. Eradication of bovine brucellosis in the 10th Region de Los Lagos.

Chile Vet Microbial 2002; 90: 45-53. factors and suggestions for disease control. Department of Clinical Sciences

116. Havas KA. A systemic review of Colorado State University, Fort Collins, brucellosis in the Kakheti region of $\mathrm{CO}$ (Ph.D. Thesis 2011). the country of Georgia: an evaluation of the disease ecology, risk factors and suggestions for disease control. Department of Clinical Sciences 